\title{
Compost Derived Substances Decrease Feed Protein N Mineralization in Swine Cecal Fermentation
}

\author{
Corrado Montoneri ${ }^{1,2}$, Enzo Montoneri ${ }^{3}$, Lorenzo Tomasso ${ }^{3} \&$ Andrea Piva $^{2}$ \\ ${ }^{1}$ Tyrrel's Equine Clinic, Sg8 9sa Royston, Hertfordshire, UK \\ ${ }^{2}$ Università di Bologna, DIMORFIPA, Ozzano dell'Emilia (BO), Italy \\ ${ }^{3}$ Università di Torino, Dipartimento di Chimica, Torino, Italy \\ Correspondence: Enzo Montoneri, Università di Torino, Dipartimento di Chimica, Torino, Italy. Tel: \\ 39-333-350-0522. E-mail: enzo.montoneri@unito.it
}

Received: November 19, 2012 Accepted: December 11, 2012 Online Published: February 5, 2013

doi:10.5539/jas.v5n3p31 URL: http://dx.doi.org/10.5539/jas.v5n3p31

\begin{abstract}
Objectives of this study were to investigate urban biowastes as sustainable source of soluble biobased products (SBO) for use in animal diet and, possibly, to assess product chemical nature-performance relationships. Thus, five different materials sourced from biowastes processed by anaerobic and/or aerobic fermentation were treated to yield five different SBO. The products were first characterized for their chemical nature. Afterwards, they were tested as diet supplements to modulate pig's cecal fermentation of a protein feed. In vitro fermentation of the protein feed was performed using the cecal content collected from slaughtered pigs as incubation liquor. The experimental plan comprised 29 treatments distributed over the 5 SBO used at 5-6 doses each in the 0.1-1.4\% concentration range, compared to a SBO free control. During the $24 \mathrm{~h}$ in vitro fermentation, gas and liquor samples were analyzed for total gas volume vs. time production, and for ammonia and volatile fatty acids concentration. The results showed the investigated SBO to be significantly different for both their chemical composition and in their effects on the measured fermentation indicators. All materials showed significant effects already at the lowest $0.1 \%$ concentration. However the SBO isolated from composted residues decreased ammonia production, whereas the SBO isolated from the digestate of the food residues' anaerobic treatment had the opposite effect. Ammonia production was found to be directly correlated with isobutyric and isovaleric production. The results clearly pointed out reduced proteolysis and $\mathrm{N}$ mineralization by $7-17 \%$ caused by compost sourced SBO. These findings have relevant implications for the economics and environmental impact of the animal production industry.
\end{abstract}

Keywords: feed supplement, food residues, proteolysis, $\mathrm{N}$ mineralization, volatile fatty acids, pigs' cecal fermentation

\section{Introduction}

For the animal production industry studies on the modulation of the animal intestinal metabolism have important economic and environmental implications. The ban of antibiotics as a growth promoter from animal feed in the European Union has motivated research on alternative ways to optimize the digestive process and increase nutrient availability (Piva et al., 2008). Thus, diet formulation including various alternative feed supplements is being considered. From the economic point of view, the intent is to obtain enhanced and safer animal growth. From the environmental point of view, the objective is to reduce the adverse impact that may be caused by animal dejections in soil and water. Indeed, deficient intestinal fermentation also results in increased proteolysis and release of toxic substances, such as ammonia and amines. For example, the typical levels of aerial ammonia in a pig farm facility range between 5 and $35 \mathrm{ppm}$ ( $\mathrm{Ji}$, McGlone, \& Kim, 2006), while suggested threshold limit values of ammonia concentration are at $25 \mathrm{ppm}$ level. Greater aerial ammonia level not only reduces the pig growth, but is also harmful to human health.

An intriguing suggestion for controlling organic $\mathrm{N}$ mineralization during anaerobic fermentation comes from the work by Ji et al. (2006). According to these authors, humic substances (HS) mined from different geological sites, and used as dietary supplements for weaning pigs, have been shown to reduce ammonia emission from manure by $16-18 \%$. Although this result prospects a promising potential effect for HS used in animal diet, availability of HS and the depletion of natural fossil sources are important critical factors for large scale exploitation of these 
substances. Recent work (Montoneri et al., 2011a) has however shown that urban bio-wastes (UBW) are a readily available cost effective source of HS-like substances. These materials contain soluble bio-organic substances (SBO) bearing chemical similarities with HS. The SBO are mixture of molecules with $67-463 \mathrm{~kg} \mathrm{~mol}^{-1}$ molecular weight containing a wide variety of $\mathrm{C}$ types and functional groups. They may be obtained in a wide variety of chemical composition and properties depending on the UBW sourcing material. They have been demonstrated suitable for a wide variety of applications in chemical and environmental technology (Montoneri et al., 2011b), and in agriculture (Sortino et al., 2012). Investigation of SBO as supplement for animal diet has not been carried out yet.

The first objective of the present study was to assess whether UBW sourced SBO performed to control feed metabolism in animal ileum. Due to the variety of materials easily available in metropolitan areas, the second objective was to investigate possible relationships between product source, chemical nature and performance for the different SBO which could be obtained. An in vivo animal study to achieve these objectives might however originate concern due to their refuse source. For this reason it was chosen in this work to perform the herewith reported in vitro fermentation study using the cecal content collected from slaughtered pigs as incubation liquor and a standard pigs' feed as fermentation substrate. Five SBO, isolated from 5 process streams of a municipal waste treatment plant were used as modulators of the fermentation process. The products were characterized for both the organic and the mineral content. They were tested for their effects on the protein feed fermentation by monitoring the production of gas, and of volatile fatty acids (VA) and ammonia.

\section{Materials and Methods}

\subsection{Soluble Bio-Organic Substances ( $S B O)$}

The SBO were obtained from 5 different materials sampled from the Acea Pinerolese Spa waste treatment plant located in Pinerolo (TO), Italy. The plant performs anaerobic and aerobic digestion of UBW. The anaerobic digestion yields biogas and a solid digestate (FORSUD) containing residual organic matter not converted to biogas The FORSUD material is mixed with home gardening and park trimmings residues (V) and/or with sewage sludge (F) and composted to yield the following materials: CV being V composted for 365 days; CVDF being a 35/55/10 w/w/w FORSUD/V/F mix composted for 110 days; CVD being a 33/67 w/w V/F mix composted for 110 days; CVF being a 35/10 w/w V/F mix composted for 110 days. These materials were further processed by alkaline hydrolysis and ultra filtration through a polysulphone membrane as previously reported (Sortino et al., 2012). The membrane retentate was brought to $\mathrm{pH}<1.5$ by adding concentrated $\mathrm{HCl}$ and centrifuged. The recovered solid phase was washed with water to $\mathrm{pH} 4$ of the final washing aliquot. The washed solid phase was dried at $60^{\circ} \mathrm{C}$ and stored $48 \mathrm{~h}$ over $\mathrm{NaOH}$ to yield the final SBO product as black solid. This was obtained in $10 \% \mathrm{w} / \mathrm{w}$ yield, relatively to the dry matter of its sourcing material. The different SBO, hereinafter identified by their sourcing refuse acronym, were characterized by the data reported in Table 1 and Table 2 . These were obtained respectively according to the methods established by A.O.A.C. (2000) and according to a previously reported protocol (Montoneri et al., 2011a).

Table 1. Analytical data (\% w/w) for SBO according to the methods by A.O.A.C. (2000)

\begin{tabular}{lccccc}
\hline & \multicolumn{3}{c}{ SBO } \\
\cline { 2 - 6 } & FORSUD & CV & CVD & CVDF & CVF \\
\hline $\mathrm{H}_{2} \mathrm{O}$ & 1.00 & 2.34 & 3.03 & 0.53 & 1.00 \\
Crude protein & 44.7 & 18.0 & 30.1 & 28.7 & 30.0 \\
Crude fat & 0.24 & 0.07 & 0.04 & 0.08 & 0.10 \\
ADF-ADF & 16.0 & 52.4 & 53.7 & 59.5 & 54.8 \\
Lignin (sa)-Lignin & 13.4 & 33.8 & 37.1 & 22.2 & 31.5 \\
$\mathrm{P}$ & 0.40 & 0.27 & 0.32 & 0.56 & 0.37 \\
\hline
\end{tabular}


Table 2. Analytical data for SBO according to Montoneri et al (2011a)

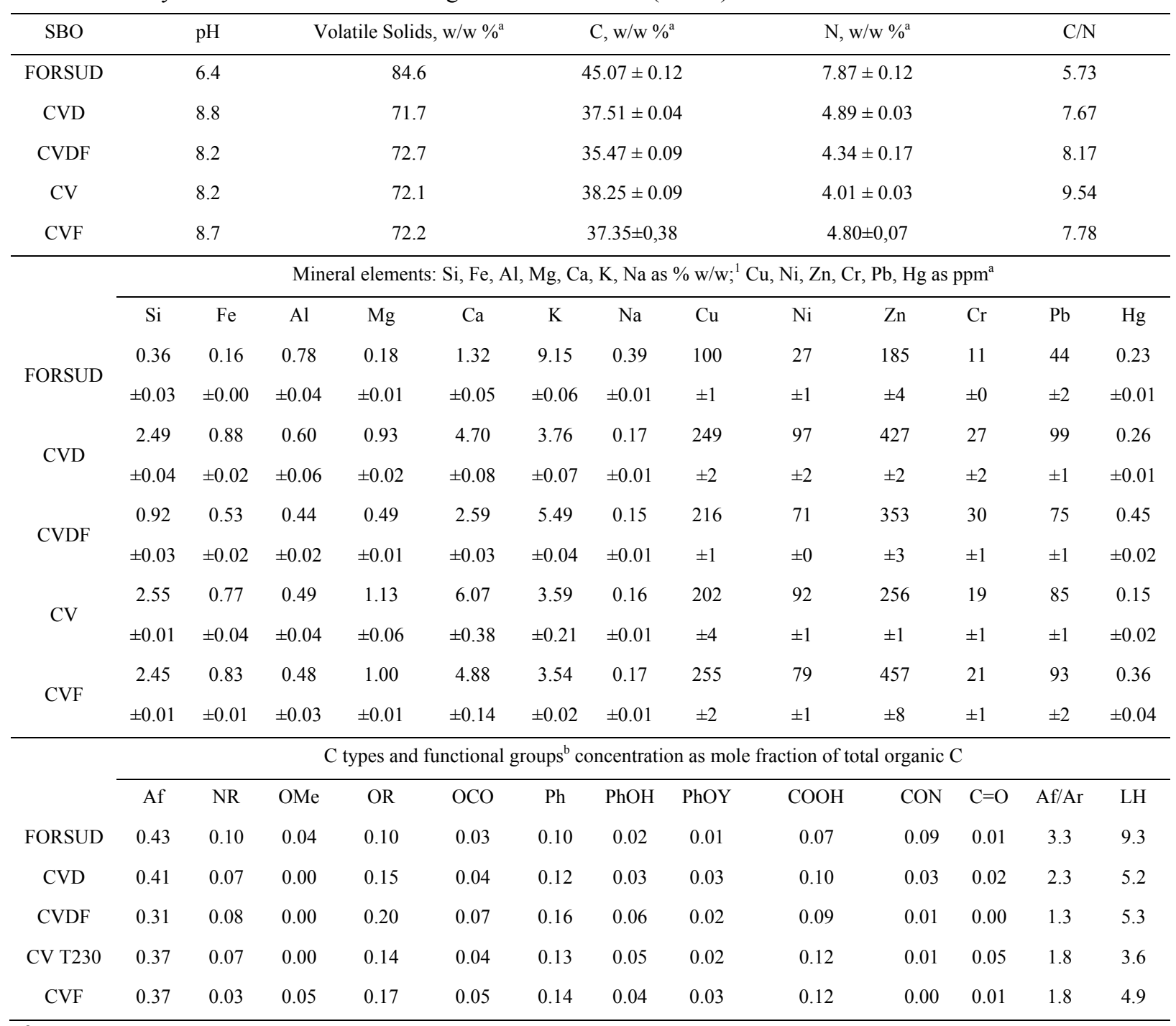

${ }^{\mathrm{a} C}$ Concentration values referred to dry matter: averages and standard deviation calculated over triplicates.

${ }^{\mathrm{b}} \mathrm{LH}=$ liphophilic to hydrophilic $\mathrm{C}$ ratio; liphophilic $\mathrm{C}=$ sum of aliphatic (Af), aromatic (Ph), methoxy (OMe), amide (CON), ammine (NR), alkoxy (RO), phenoxy (PhOY) and anomeric (OCO) $\mathrm{C}$ atoms; hydrophilic $\mathrm{C}=$ sum of carboxylic acid $(\mathrm{COOH})$, phenol $(\mathrm{PhOH})$ and ketone $(\mathrm{C}=\mathrm{O}) \mathrm{C}$.

\subsection{Feed Substrate for Fermentation}

A standard feed for pigs supplied by Vetagro s.r.l., Reggio Emilia, Italy, was used in the experiment. The standard feed was pre-digested to simulate cecal fermentation as previously described (Casadei, Grilli, \& Piva, 2009): i.e. incubation in acid pepsin solution at $37^{\circ} \mathrm{C}$ for $4 \mathrm{~h}$, followed by incubation in pancreatin solution at $\mathrm{pH}$ 7.5 and $37^{\circ} \mathrm{C}$ for $4 \mathrm{~h}$. After enzymatic digestion, the preparation was centrifuged, washed twice with distilled water, recentrifuged, and dried at $60^{\circ} \mathrm{C}$ overnight. The pre-digested fermentation feed substrate was characterized by the following analytical data as $\% \mathrm{w} / \mathrm{w}$ referred to dry matter: crude protein 4.44 , crude fiber 8.68 , crude fats 4.96 , and starch 45.72 .

\subsection{In Vitro Intestinal Fermentation}

Solutions of SBO in aqueous $\mathrm{NaOH}$ at $\mathrm{pH} 8$ were obtained at the following $\% \mathrm{w} / \mathrm{w}$ concentrations: $11.7 \% \mathrm{CVDF}$ and CVF respectively, $12.0 \% \mathrm{CV}, 8.50 \% \mathrm{CVD}$ and $4.83 \%$ FORSUD. Cecal contents were collected from pigs immediately after slaughtering and filtered before use. These were used as incubation liquor. The SBO solutions, the feed substrate and the cecal content were used to prepare the fermentation liquors diluted with McDougall buffer. These contained $0.40 \%$ feed substrate, $31 \%$ cecal content, $60 \%$ buffer, and variable amounts of SBO 
according to the data reported in Table 3 . The final $\mathrm{pH}$ of the freshly prepared fermentation liquor was 6.5. For each treatment fermentations at $39^{\circ} \mathrm{C}$ for $24 \mathrm{~h}$ were performed in 5 replicates, both in $10 \mathrm{~mL}$ glass syringes and in vessels respectively containing 5 and $25 \mathrm{~mL}$ of total liquor volume. Gas production was measured as described by Menke et al. (1979), using glass syringes and recording the cumulative volume of gas produced every $30 \mathrm{~min}$. Samples of fermentation fluid were collected from each vessel 0, 4, 8 and $24 \mathrm{~h}$ after incubation for ammonia and VA analysis. Chemical analyses of feed and fermentation liquor were performed as previously described (Piva et al., 2002).

Table 3. Modified Gompertz equation parameters (GEP) ${ }^{\mathrm{a}}$ calculated from experimental gas volume data fitting for in vitro pig cecal fermentation in the presence of SBO from different source at $0-1.4 \% \mathrm{w} / \mathrm{V}$ concentration; statistical parameters resulting from ANOVA analysis of variance ( $\mathrm{F}$ and $\mathrm{Pr}$ ) and from multiple comparison Tuckey's test ${ }^{\mathrm{b}}$

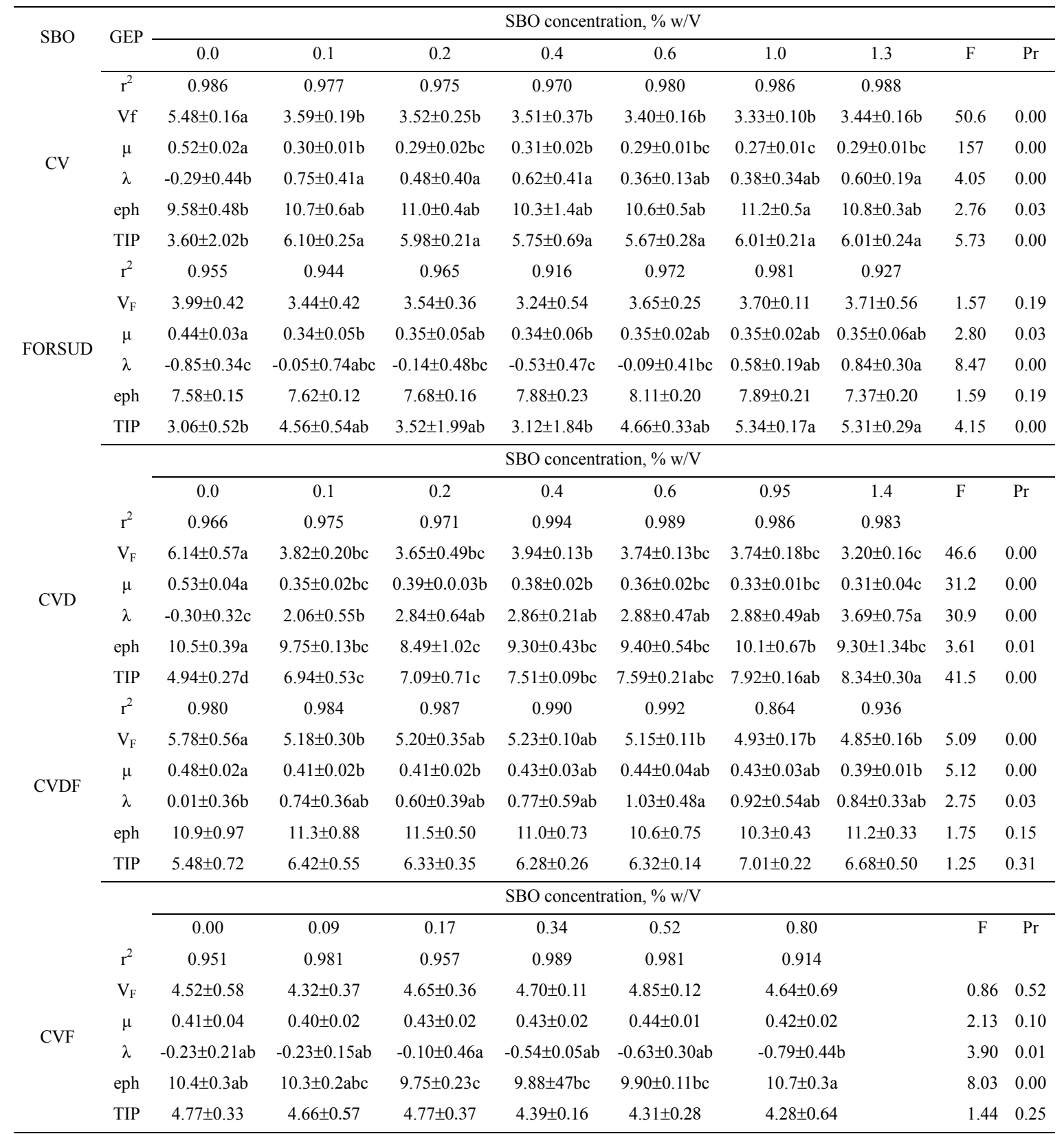

${ }^{a}$ Values are means \pm standard deviation calculated over five replicates for each treatment; $r^{2}=$ correlation coefficient; $\mathrm{V}_{\mathrm{F}}=$ maximum volume of gas produced $(\mathrm{mL}) ; \mu=$ maximum rate of gas production $\left(\mathrm{mL} \mathrm{h}^{-1}\right) ; \lambda=$ lag time (h), eph = exponential phase duration (h); TIP = time (h) to inflection point.

${ }^{b}$ Values in the same row identified by different letters differ significantly at $95 \%$ confidence level: $a>b>c$. 


\subsection{Modeling and Statistics}

The Gompertz bacterial growth model was used to fit gas production data, assuming that the substrate level limits growth in a logarithmic relationship. The Gompertz equation for gas production is as follows:

$$
V_{T}=V f \exp \left\{-\exp \left[1+\left(\mu_{m} e / V_{F}\right)(\lambda-T)\right]\right\}
$$

where $\mathrm{V}_{\mathrm{T}}=$ volume of gas produced at time $\mathrm{T}, \mathrm{T}=$ fermentation time, $V f=$ maximum volume of gas produced, $\mu_{\mathrm{m}}=$ maximum rate of gas production, which occurs at the point of inflection of the gas curve, and $\lambda=$ the lag time, as the time-axis intercept of a tangent line at the point of inflection. The duration of the exponential phase was calculated from the parameters of the modified Gompertz equation, using the following equation:

$$
\text { exponential phase }(h)=V f /\left(\mu_{m} e\right)\left\{1-\ln \left[\left(3-5^{1 / 2}\right) / 2\right]\right\}
$$

The time required from the beginning of the fermentation to the maximum rate of gas production was calculated with the following equation:

$$
\text { time from time } 0 \text { to inflection point (TIP, h) }=\lambda+\text { (exponential phase/2) }
$$

Curve fitting and statistical analysis was carried out using the program GraphPad Prism 3.0 (GraphPad Software, San Diego, CA) and the SAS (SAS Institute, Inc. 1996) statistical method (Version 6.12). For each SBO, dose treatments were compared for their average values by Anova analysis of variance and unpaired t-Student test. Differences between gas production parameters, ammonia and VA data due to SBO dose were considered statistically significant at $\mathrm{P}<0.05$.

\section{Results}

Assessment of SBO chemical nature was the first step of the experimental work performed in this study. This was not the main objective, but it was necessary in order to achieve the objectives stated in the Introduction section. The SBO were characterized according to the methods established for feed analyses by A.O.A.C. (2000) to yield the proximate compounds' concentration values reported in Table 1. More chemical information (Table 2) was obtained by analyzing the mineral content and characterizing further the organic fraction by its type and content of $\mathrm{C}$ types and functional groups.

The data for the products' performance in the in vitro intestinal fermentation of the probe feed substrate described in the experimental section are reported in Table 3-6. In more details, Table 3 reports the gas production parameters calculated by fitting equations 1-3 to the experimental gas production vs. time data. As differences between treatments were generally found negligible at the 4th hour, but to increase afterwards until the 24th hour, data for the other fermentation indicators are reported only for the samples withdrawn at the 24th hour: i.e. $\mathrm{pH}$ in Table 4, and ammonia and VA production in Table 5 and Table 6 respectively.

Table 4. Fermentation liquor $\mathrm{pH}^{\mathrm{a}}$ after $24 \mathrm{~h}$ in vitro pig cecal fermentation in the presence of SBO from different source at $0-1.4 \% \mathrm{w} / \mathrm{V}$ concentration; statistical parameters resulting from ANOVA analysis of variance $(\mathrm{F}$ and $\mathrm{Pr})$ and from multiple comparison Tuckey's test ${ }^{\mathrm{b}}$

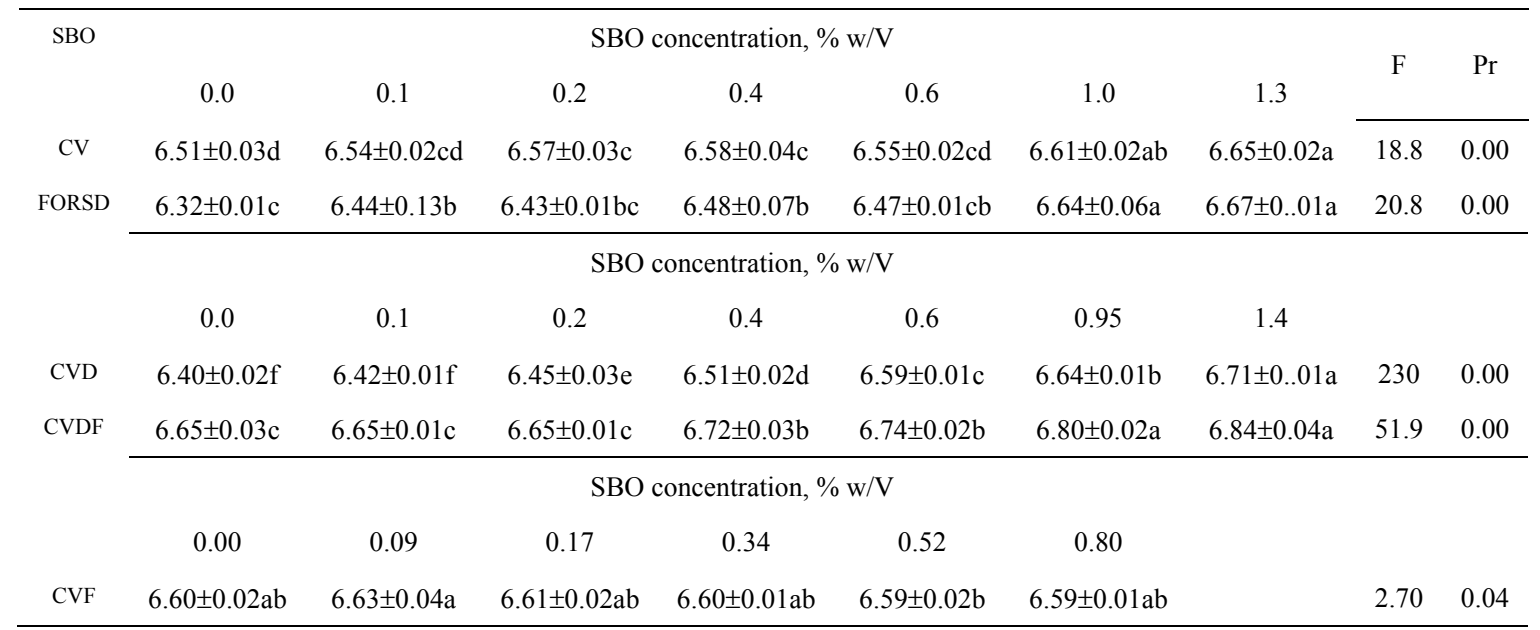

${ }^{a}$ Values are means \pm standard deviation calculated over five replicates for each treatment.

${ }^{b}$ Values in the same row identified by different letters differ significantly at $95 \%$ confidence level: $a>b>c>$ $\mathrm{d}>\mathrm{e}>\mathrm{f}$. 


\section{Discussion}

\subsection{Chemical Differences between the Investigated SBO}

According to Table 1 the investigated SBO appear composed mostly by protein, lignin, cellulose and silicates, whereas fats are at rather low concentration. The $\mathrm{C}$ types and functional groups concentration values (Table 2), calculated from 13C NMR spectroscopy, potentiometric titration and $\mathrm{C}$ and $\mathrm{N}$ micro analytical experimental data, show that in reality the cellulose material is quite low. This is demonstrated by the rather low fraction $(0.03-0.04)$ of the anomeric (OCO) $\mathrm{C}$. This result is consistent with the product source having undergone anaerobic and/or aerobic fermentation. Due to this treatment and the subsequent hydrolytic reaction of the recovered material, the SBO products cannot be classified simply as mixture of the proximate compounds listed in Table 1 . They should rather be viewed as biodegraded lignocellulose matter containing Table $2 \mathrm{C}$ types and functional groups, which represent the memory of the parent proximate compounds present in the sourcing vegetable or food waste material. According to their different origin, the SBO listed in Table 2 appear to have different chemical compositions. They are mixture of molecules (Montoneri et al., 2011a), comprising a range of molecular weight and a variety of distribution of $\mathrm{C}$ types and functional groups. One way to rank them for their different chemical nature is by the $\mathrm{LH}$ and $\mathrm{Af} / \mathrm{Ar}$ values reported in Table 2 which encompass all $\mathrm{C}$ types and functional groups. According to the definitions given in the Table footnotes, LH is an index of the degree lipophilicity, while Af/Ar indicates the type of lipophilicity. Thus, based on Table 2 data, it may be observed that FORSUD and CV exhibit the largest differences. Indeed the former has the lowest values for the ash content, for the $\mathrm{C} / \mathrm{N}$ ratio, and for the content of $\mathrm{COOH}$ acid groups, while exhibiting the highest values for the $\mathrm{LH}$ and $\mathrm{Af} / \mathrm{Ar}$ parameters. This indicates FORSUD as the most lipophilic, aliphatic and least acidic material, characterized by the highest content of organic N. At the other extreme of such empirical chemical scale, $\mathrm{CV}$ has the highest $\mathrm{C} / \mathrm{N}$ ratio, the highest content of $\mathrm{COOH}$ acid groups and the lowest $\mathrm{LH}$ values. Thus, $\mathrm{CV}$ appears to be the most hydrophilic acid material, characterized by the lowest content of organic $\mathrm{N}$. The above SBO have also significantly different mineral composition. FORSUD has the lowest content of mineral elements, particularly $\mathrm{Si}, \mathrm{Ca}, \mathrm{Mg}, \mathrm{Fe}$ and heavy elements, while exhibiting the highest content of alkaline metals. The CV SBO is distinguished for the highest content of $\mathrm{Ca}$ and $\mathrm{Mg}$.

\subsection{In Vitro Intestinal Fermentations: Gas Production}

Table 3 shows that the gas production vs. time data fit very well the Gompertz equation yielding a correlation coefficient (r) which ranges from 0.929 to 0.996 . FORSUD and CVF do not seem to cause any significant effects on gas production parameters. On the contrary, the other three SBO cause mainly decrease of Vf and $\mu$. These effects appear already at the lowest $0.1 \%$ SBO concentration. Their magnitude does not seem to change significantly upon raising the concentration to the highest experimental 1.3-1.4\% value. The CV and CVD SBO cause the major decreases of Vf and $\mu$. These may be calculated to span from 33 to $44 \%$ over the whole SBO concentration range, relatively to the control. The corresponding CVDF effects are well lower, at $12-13 \%$ decrease level for both Vf and $\mu$.

\subsection{In Vitro Intestinal Fermentations: $p H$}

Table 4 shows that all SBO, except CVF, cause a moderate increase of $\mathrm{pH}$, within $0.03-0.35$ units, over the experimental SBO concentration range. The $\mathrm{pH}$ increase seems to bear no relationship with the effects on gas production parameters.

\subsection{In Vitro Intestinal Fermentations: Ammonia Production}

Table 5 shows that, relatively to the control, CV and CVF cause $8-17 \%$ decrease of ammonia production. This effect seems to be higher upon increasing the SBO concentration in the fermentation liquor. The CVDF effect is of lower magnitude (8\%) across the whole SBO concentration range. The CVD effect appears demonstrated statistically significant only at $0.2 \%$ SBO concentration. The FORSUD SBO is the only one showing the opposite effect; i.e. it causes increased ammonia production by $13-30 \%$ over its concentration range. The type and magnitude of the effect on ammonia production does not seem related to the effects on $\mathrm{pH}$ and gas production. 
Table 5. Ammonia $\left(\mathrm{mmol} \mathrm{L}^{-1}\right)^{\mathrm{a}}$ production after $24 \mathrm{~h}$ in vitro pig cecal fermentation in the presence of SBO from different source at $0-1.4 \% \mathrm{w} / \mathrm{V}$ concentration; statistical parameters resulting from ANOVA analysis of variance (F and Pr) and from multiple comparison Tuckey's test ${ }^{\mathrm{b}}$

\begin{tabular}{|c|c|c|c|c|c|c|c|c|c|}
\hline \multirow[t]{2}{*}{ SBO } & \multicolumn{7}{|c|}{ SBO concentration, $\% \mathrm{w} / \mathrm{V}$} & \multirow{2}{*}{$\mathrm{F}$} & \multirow{2}{*}{$\operatorname{Pr}$} \\
\hline & 0.0 & 0.1 & 0.2 & 0.4 & 0.6 & 1.0 & 1.3 & & \\
\hline $\mathrm{CV}$ & $30.0 \pm 0.5 \mathrm{a}$ & $27.5 \pm 0.5 b$ & $25.9 \pm 0.4 \mathrm{c}$ & $25.5 \pm 0.8 \mathrm{~cd}$ & $25.0 \pm 0.4 \mathrm{~d}$ & $24.5 \pm 0.4 \mathrm{~d}$ & $25.2 \pm 0.4 \mathrm{~cd}$ & 71.05 & 0.00 \\
\hline FORSUD & $19.8 \pm 1.4 \mathrm{c}$ & $19.8 \pm 1.1 \mathrm{c}$ & $21.8 \pm 0.7 b$ & $22.8 \pm 0.7 \mathrm{~b}$ & $22.8 \pm 0.5 b$ & $25.1 \pm 0.4 \mathrm{a}$ & $26.2 \pm 0.8 \mathrm{a}$ & 38.8 & 0.00 \\
\hline \multicolumn{10}{|c|}{ SBO concentration, $\% \mathrm{w} / \mathrm{V}$} \\
\hline & 0.0 & 0.1 & 0.2 & 0.4 & 0.6 & 0.95 & 1.4 & & \\
\hline CVD & $24.6 \pm 0.7 \mathrm{a}$ & $23.0 \pm 1.5 \mathrm{ab}$ & $22.4 \pm 0.6 b$ & $23.4 \pm 1.3 \mathrm{ab}$ & $23.6 \pm 0.6 \mathrm{ab}$ & $24.7 \pm 0.6 \mathrm{a}$ & $24.4 \pm 0.8 \mathrm{a}$ & 4.25 & 0.00 \\
\hline CVDF & $29.6 \pm 0.7 \mathrm{a}$ & $27.7 \pm 0.5 \mathrm{bc}$ & $26.7 \pm 0.5 \mathrm{~cd}$ & $26.5 \pm 0.7 \mathrm{~d}$ & $26.8 \pm 0.4 \mathrm{~cd}$ & $27.0 \pm 0.6 \mathrm{bcd}$ & $28.2 \pm 0.8 b$ & 16.30 & 0.00 \\
\hline \multicolumn{10}{|c|}{ SBO concentration, $\% \mathrm{w} / \mathrm{V}$} \\
\hline & 0.00 & 0.09 & 0.17 & 0.34 & 0.52 & 0.80 & & & \\
\hline CVF & $27.1 \pm 0.5 \mathrm{a}$ & $24.1 \pm 0.7 b$ & $22.4 \pm 0.3 \mathrm{c}$ & $22.4 \pm 0.4 \mathrm{c}$ & $22.3 \pm 0.3 \mathrm{c}$ & $22.5 \pm 0.5 \mathrm{c}$ & & 79.64 & 0.00 \\
\hline
\end{tabular}

${ }^{\mathrm{a}}$ Values are means \pm standard deviation calculated over five replicates for each treatment.

${ }^{b}$ Values in the same row identified by different letters differ significantly at $95 \%$ confidence level: $a>b>c>d$.

\subsection{In vitro Intestinal Fermentations: VA Production}

Table 6 contains the experimental data collected for the production of the single acetic (C2), propionic (C3), n-butyric (C4), iso-butyric ( $\mathrm{C} 4 \mathrm{i})$, n-valeric (C5) and iso-valeric (C5i) acids, and for their sum reported as total volatile acids (TA). The results show that changes of VA production correlate with changes in ammonia production; i.e., relatively to the control, decrease of ammonia corresponds to decrease of all VA except C2, with decreases of isoacids being of relatively higher magnitude. Indeed CV and CVF, shown above (Table 5) to cause the largest decrease in ammonia production, cause also the largest decreases of C4 (11-18\%) and C5 (25-31\%), and more so of C4i (15-23\%) and C5i (32-36\%) acids. The CVDF SBO, ranking second for the magnitude of the ammonia decreasing effect, is also second for the magnitude of the effect on the $\mathrm{C} 4$ and $\mathrm{C} 5$, normal and isoacids, ranging from 8 to $15 \%$. The CVD SBO, causing no effect on ammonia production (Table 4), does not cause any effect of VA production, except for the increase of C2. Finally FORSUD causes increase of production of both ammonia and, more so, of all VA. The different effects on each fatty acid production result in significant changes on the VA production ratios reported in Table 7 . The meaning of these changes is discussed hereinafter. 
Table 6. Volatile fatty acids (VA) production $\left(\mathrm{mmol} \mathrm{L}^{-1}\right)^{\mathrm{a}}$ after $24 \mathrm{~h}$ in vitro pig cecal fermentation in the presence of SBO from different source at $0-1.4 \% \mathrm{w} / \mathrm{V}$ concentration; statistical parameters resulting from ANOVA analysis of variance ( $\mathrm{F}$ and Pr) and from multiple comparison Tuckey's test ${ }^{\mathrm{b}}$



${ }^{\mathrm{a}}$ Values are means \pm standard deviation calculated over five replicates for each treatment.

${ }^{b}$ Values in the same row identified by different letters differ significantly at $95 \%$ confidence level: $a>b>c>d$.

${ }^{\mathrm{c}}$ Total volatile fatty acids (TA), acetic acid (C2), propionic acid (C3), n-butyric acid (C4), iso-butyric acid (C4i), nvaleric acid (C5), iso-valeric acid (C5i). 
Table 7. Volatile fatty acids' production ratios (VAR) after $24 \mathrm{~h}$ in vitro fermentation of pig caecum in the presence of $\mathrm{SBO}$ from different source at $0-1.4 \% \mathrm{w} / \mathrm{V}$ concentration; statistical parameters resulting from ANOVA analysis of variance ( $\mathrm{F}$ and $\mathrm{Pr}$ ) and from multiple comparison Tuckey's test ${ }^{\mathrm{b}}$

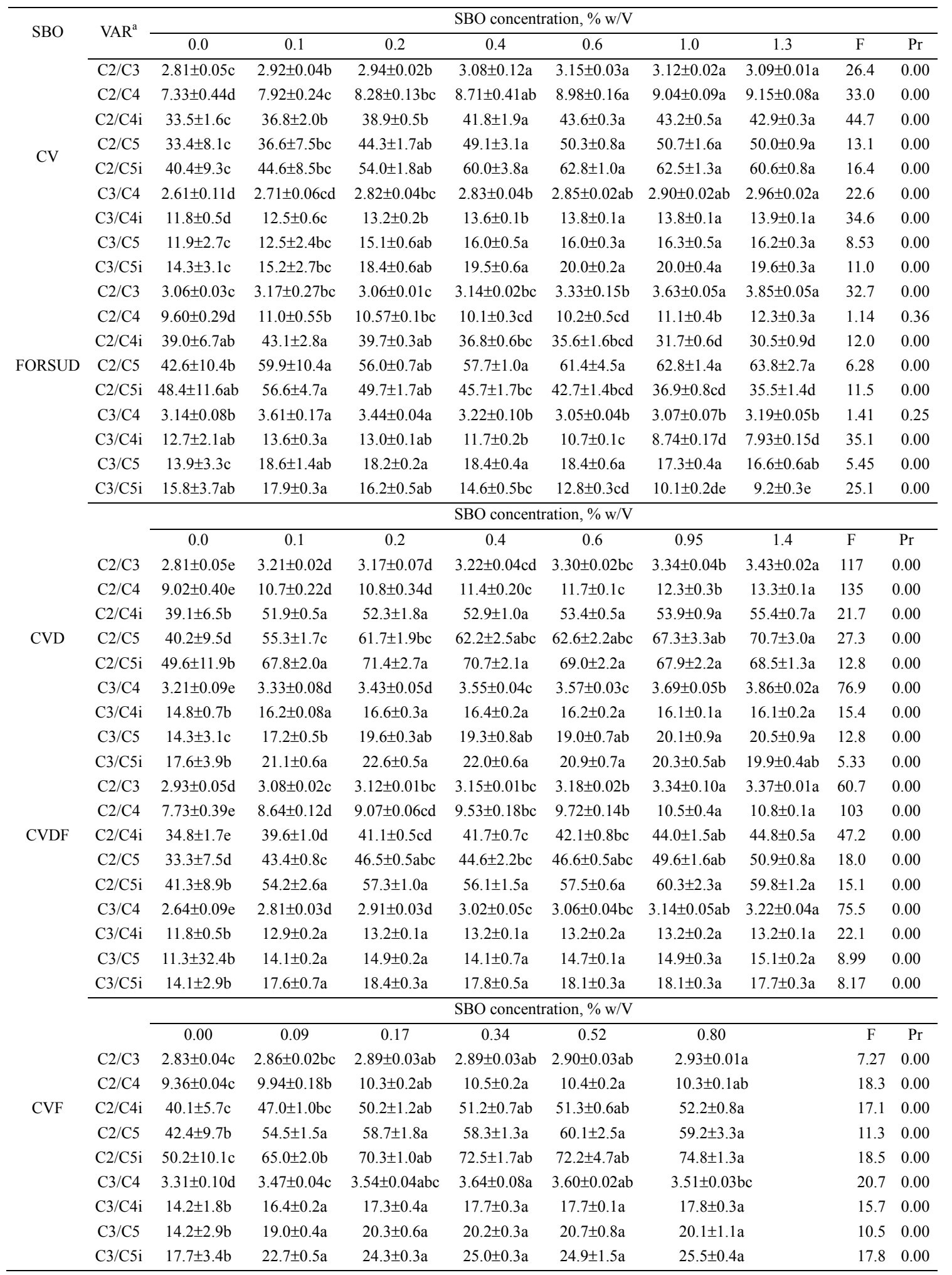

${ }^{a}$ Legends for single fatty acids as in Table 6; values are means \pm standard deviation calculated over five replicates for each treatment.

${ }^{b}$ Values in the same row identified by different letters differ significantly at $95 \%$ confidence level: $a>b>c>d>$ e. 


\subsection{Overall Remarks on SBO Effects and Their Chemical Nature-Performance Relationships}

It may be observed from the collected experimental data that this work investigated the effects of a high number of treatments on the protein feed substrate fermentation; i.e. 29 treatments distributed over 5 different SBO materials used at 5-6 doses each, in addition to the control experiment. To this purpose both the gas and liquor phases were sampled at different times from the start and analyzed for production of total gas volume, and of liquor $\mathrm{pH}$, ammonia and volatile fatty acids. Table 8 summarizes the effects observed from collection and statistical elaboration of about 1800 experimental data. From the statistical treatment of Table 3-7 data, effects are demonstrated in most cases already at the lowest $0.1 \% \mathrm{w} / \mathrm{w}$ SBO concentration. Where the effect magnitude in Table 8 is indicated as value range, the effect magnitude was found to increase upon increasing the SBO concentration. Where a single value is reported in Table 8, the effect magnitude was found constant throughout the investigated SBO concentration range. Where no value is indicated in Table 8, no effect was observed. It appears that all SBO increase the $\mathrm{C} 2 / \mathrm{C} 3$ ratio from 9 to $22 \%$. Consistently with similar effect reported for the lactic acid bacteria produced bacteriocin pediocin A (Casadei et al., 2009), the increasing $\mathrm{C} 2 / \mathrm{C} 3$ ratio suggests a greater metabolism of cellulolytic bacteria. The $\mathrm{C} 2 / \mathrm{C} 4, \mathrm{C} 2 / \mathrm{C} 5, \mathrm{C} 3 / \mathrm{C} 4$ and $\mathrm{C} 3 / \mathrm{C} 5$ ratios seem to increase too as a result of all treatments. On the contrary, the different SBO appear to affect in different way the ratios of the $\mathrm{C} 2$ and $\mathrm{C} 3$ acids to the iso-acids production and the emission of ammonia. In essence, FORSUD decreases the $\mathrm{C} 2 / \mathrm{C} 4 \mathrm{i}, \mathrm{C} 2 / \mathrm{C} 5 \mathrm{i}, \mathrm{C} 3 / \mathrm{C} 4 \mathrm{i}$ and $\mathrm{C} 3 / \mathrm{C} 5 \mathrm{i}$ production ratios from 20 to $34 \%$. This same SBO also appears to increase the ammonia emission from 13 to $29 \%$. On the contrary, all other SBO appear to increase the $\mathrm{C} 2 / \mathrm{C} 4 \mathrm{i}, \mathrm{C} 2 / \mathrm{C} 5 \mathrm{i}$, $\mathrm{C} 3 / \mathrm{C} 4 \mathrm{i}$ and $\mathrm{C} 3 / \mathrm{C} 5 \mathrm{i}$ production ratios from 9 to $48 \%$ and to decrease ammonia emission by $7-17 \%$. The data seem to point out that the investigated SBO could be divided in two categories according to their sourcing material: i.e. FORSUD isolated from anaerobically fermented material and all others isolated from aerobically fermented materials. The former does not affect the gas production parameters. However, it increases the production of ammonia and of the volatile fatty acids isomers $\mathrm{C} 4 \mathrm{i}$ and $\mathrm{C} 5 \mathrm{i}$, and causes a net decrease of $\mathrm{C} 2 / \mathrm{C} 4 \mathrm{i}$, $\mathrm{C} 3 / \mathrm{C} 4 \mathrm{i}, \mathrm{C} 2 / \mathrm{C} 5 \mathrm{i}$ and $\mathrm{C} 3 / \mathrm{C} 5 \mathrm{i}$ ratios. On the contrary, the $\mathrm{SBO}$ isolated from compost decrease the volume and rate of gas production and/or the production of ammonia and of the volatile fatty acids isomers $\mathrm{C} 4 \mathrm{i}$ and $\mathrm{C} 5 \mathrm{i}$, causing also a net increase of $\mathrm{C} 2 / \mathrm{C} 4 \mathrm{i}, \mathrm{C} 3 / \mathrm{C} 4 \mathrm{i}, \mathrm{C} 2 / \mathrm{C} 5 \mathrm{i}$ and $\mathrm{C} 3 / \mathrm{C} 5 \mathrm{i}$ ratios. Consistently with similar effect reported for other products (Piva et al., 1995), the lower molar proportion of isoacis, coupled to the reduced ammonia production, indicates lower proteolitic activity. These isoacids, formed from the deamination and/or decarboxylation of amino acids, are indicative of protein catabolism extent. Figure 1 shows the plot of all ammonia vs. $\mathrm{C} 4 \mathrm{i}$ and $\mathrm{C} 5 \mathrm{i}$ data collected in the present work. The data belong to two different populations, i.e. those collected in the FORSUD treatment and all others. Table 9 reports the results of the linear regression analysis of Fig. 1 data demonstrating a direct correlation of ammonia concentration with the single isoacids or with their sum. The ammonia data do not correlate with the data obtained for $\mathrm{C} 2, \mathrm{C} 3, \mathrm{C} 4$ and $\mathrm{C} 5$. This further supports the argument that changes in the concentration of both ammonia and the two C4i and C5i isoacids are indicative of the extent of proteolysis coupled to $\mathrm{N}$ mineralization. A possible reason for the observed SBO effects on ammonia reduction might be the concentration of $\mathrm{COOH}$ and/or $\mathrm{PhOH}$ groups. Indeed $\mathrm{CV}, \mathrm{CVF}$ and CVDF, having the highest phenol and total acid groups' concentrations, seem to yield the highest reduction of ammonia formation. A similar effect has been observed by citric, fumaric and malic acid blend (Piva et al., 2002). However, these carboxylic acids were found not to stimulate fiber digestion, whereas the SBO isolated from compost matter are capable of stimulating fiber digestion and reduce proteolysis at the same time. The overall effects, which have are observed with SBO, are more similar to those observed with pediocin A. This protein bacteriocin, showing antimicrobial properties against gram-positive bacteria populating the swine hindgut, was found both to stimulate cellulolytic activity and reduce proteolysis (Casadei et al., 2009). Aside from this, the data do not allow further speculations on the relationship between SBO chemical composition, properties and effects. There might be a possible contribution of the higher content of mineral elements to determine the different behavior exhibited by the compost sourced SBO compared to FORSUD SBO. Macroand micro elements such as $\mathrm{Ca}, \mathrm{P}, \mathrm{Mg}, \mathrm{Na}, \mathrm{K}, \mathrm{Fe}, \mathrm{Cu}, \mathrm{Mn}, \mathrm{Zn}$, Se, Co have been reported to affect the fermentation processes occurring in animals' digestive tract (Mista, 2007). 

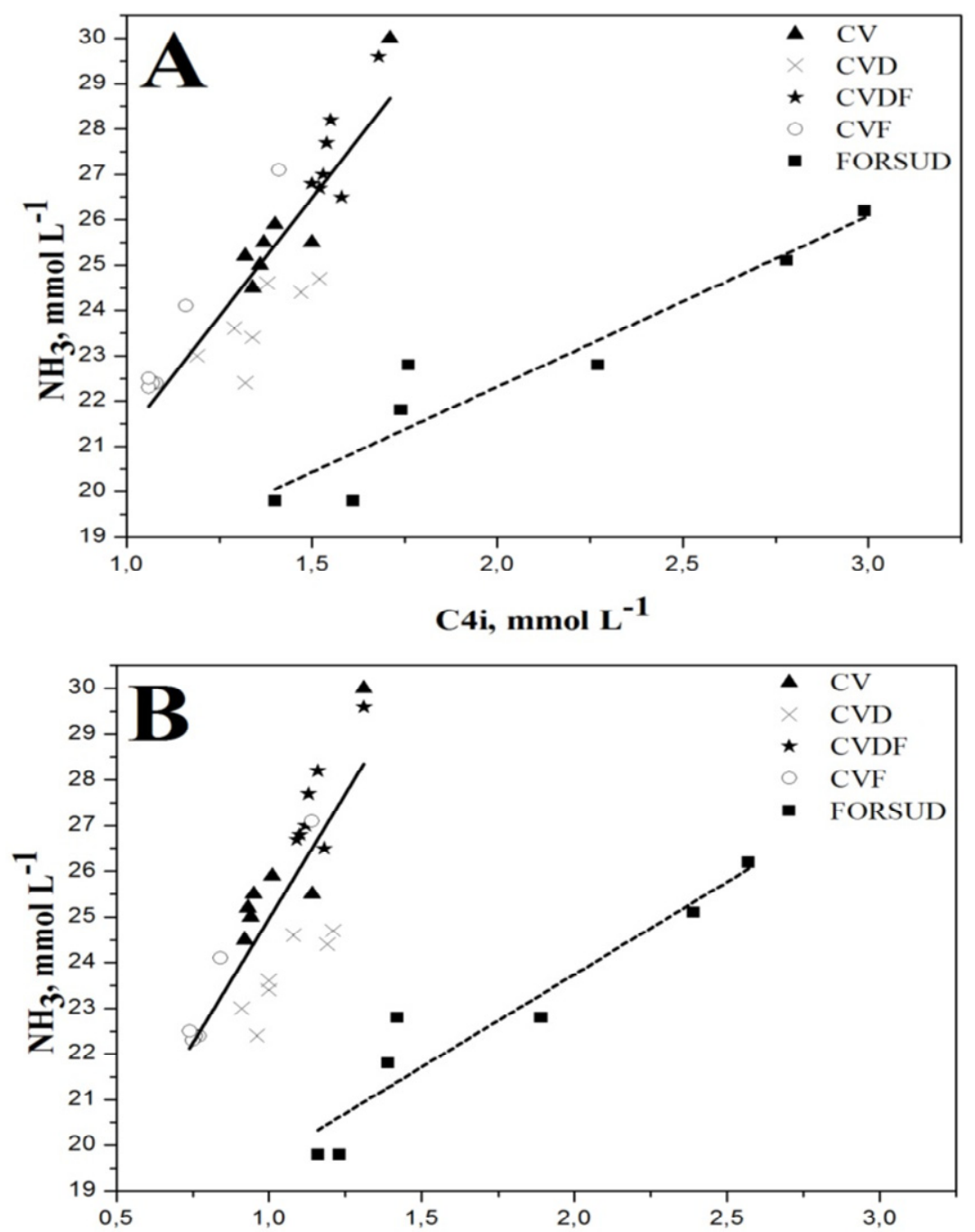

C5i, $\mathbf{m m o l ~ L}^{-1}$

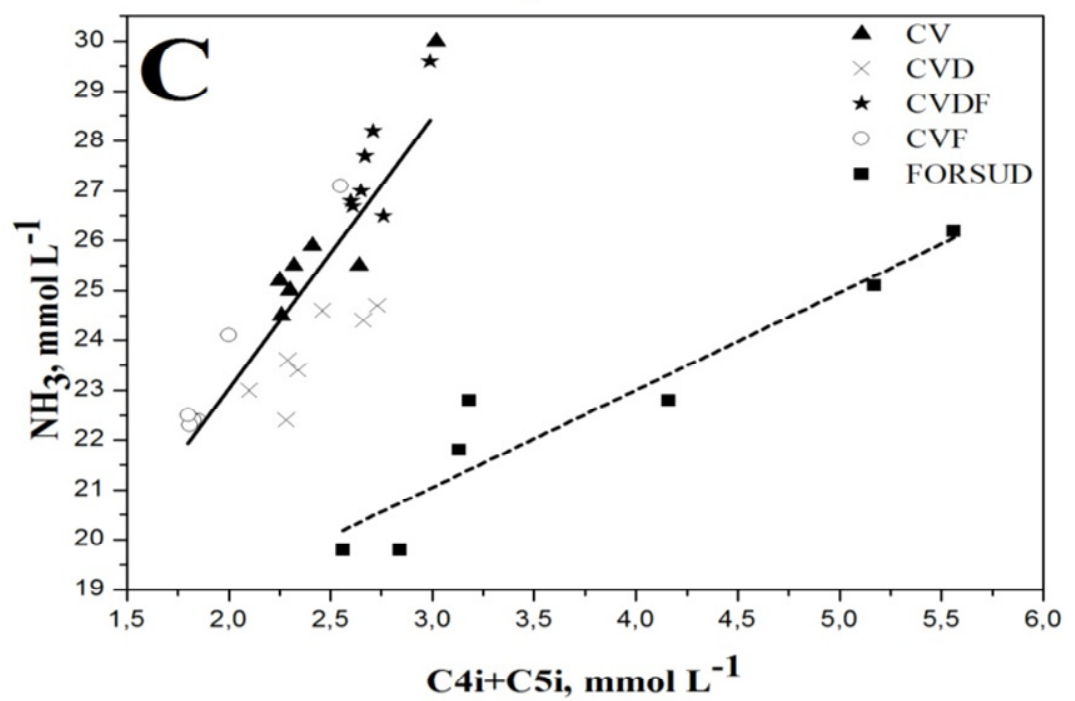

Figure 1. Plot of ammonia emission vs. (A) iso-butyric $\mathrm{C} 4 \mathrm{i}$, (B) iso-valeric $\mathrm{C} 5 \mathrm{i}$, and (C) total iso-acids $\mathrm{C} 4 \mathrm{i}+\mathrm{C} 5 \mathrm{i}$ concentration 
Table 8. Increase or decrease (-), as \% relatively to the control value, caused by SBO with different molecular features on fermentation parameters; $\div$ indicates range

\begin{tabular}{|c|c|c|c|c|c|}
\hline & FORSUD & $\mathrm{CV}$ & CVD & CVDF & CVF \\
\hline \multicolumn{6}{|c|}{$\begin{array}{l}\text { Molecular features } \\
\text { (mole fraction) }\end{array}$} \\
\hline $\mathrm{COOH}$ & 0.07 & 0.12 & 0.10 & 0.09 & 0.12 \\
\hline $\mathrm{PhOH}$ & 0.02 & 0.05 & 0.03 & 0.06 & 0.04 \\
\hline $\mathrm{COOH}+\mathrm{PhOH}$ & 0.09 & 0.17 & 0.13 & 0.15 & 0.16 \\
\hline \multicolumn{6}{|l|}{$\begin{array}{l}\text { Fermentation } \\
\text { Parameters }\end{array}$} \\
\hline $\mathrm{Vf}$ & & -37 & -40 & -12 & \\
\hline$\mu$ & & -44 & -33 & -13 & \\
\hline pH & $0.12 \div 0.35$ & $0.06 \div 0.14$ & $0.03 \div 0.31$ & $0.07 \div 0.19$ & \\
\hline $\mathrm{NH}_{3}$ & $13 \div 29$ & $-8 \div 17$ & -7 & -8 & $-11 \div 17$ \\
\hline $\mathrm{TA}$ & 55 & & 29 & 11 & \\
\hline $\mathrm{C} 2$ & 62 & & 41 & 18 & \\
\hline $\mathrm{C} 3$ & 34 & -7 & & & \\
\hline $\mathrm{C} 4$ & 40 & $-13 \div 18$ & & $-6 \div 13$ & -11 \\
\hline $\mathrm{C} 4 \mathrm{i}$ & $62 \div 106$ & $-15 \div 21$ & & -8 & -23 \\
\hline $\mathrm{C} 5$ & & -25 & & -15 & -31 \\
\hline $\mathrm{C} 5 \mathrm{i}$ & $63 \div 114$ & -36 & & -14 & -32 \\
\hline $\mathrm{C} 2 / \mathrm{C} 3$ & $9 \div 22$ & $4 \div 11$ & 13 & $6 \div 14$ & 15 \\
\hline $\mathrm{C} 2 / \mathrm{C} 4$ & $12 \div 28$ & $11 \div 22$ & $19 \div 47$ & $12 \div 40$ & $8 \div 11$ \\
\hline $\mathrm{C} 2 / \mathrm{C} 4 \mathrm{i}$ & -20 & $13 \div 28$ & 36 & $16-25$ & 27 \\
\hline $\mathrm{C} 2 / \mathrm{C} 5$ & 43 & 46 & 57 & 41 & 37 \\
\hline $\mathrm{C} 2 / \mathrm{C} 5 \mathrm{i}$ & -25 & 48 & 39 & 39 & 41 \\
\hline $\mathrm{C} 3 / \mathrm{C} 4$ & 12 & $6 \div 11$ & $5 \div 20$ & $6 \div 22$ & $6 \div 9$ \\
\hline $\mathrm{C} 3 / \mathrm{C} 4 \mathrm{i}$ & $-16 \div 34$ & $6 \div 17$ & 9 & 11 & 22 \\
\hline $\mathrm{C} 3 / \mathrm{C} 5$ & 29 & 34 & 29 & 29 & 41 \\
\hline $\mathrm{C} 3 / \mathrm{C} 5 \mathrm{i}$ & -26 & 36 & 27 & 27 & 38 \\
\hline
\end{tabular}

Table 9. Intercept (a), slope (b) and coefficient ( $r$ ) of the regression analysis of Figure 1 data according to the linear equation $\mathrm{y}=\mathrm{a}+\mathrm{b} \mathrm{x}, \mathrm{y}=$ ammonia concentration, $\mathrm{x}=$ isoacid concentration

\begin{tabular}{|c|c|c|}
\hline $\mathrm{x}$ & SBO & Results \\
\hline \multirow{6}{*}{$\mathrm{C} 4 \mathrm{i}$} & & $10.79 \pm 1.55$ \\
\hline & CV, CVD, CVDF, CVF & $10.46 \pm 1.11$ \\
\hline & & 0.88 \\
\hline & \multirow{3}{*}{ FORSUD } & $14.79 \pm 1.22$ \\
\hline & & $3.76 \pm 0.57$ \\
\hline & & 0.94 \\
\hline \multirow{6}{*}{$\mathrm{C} 5 \mathrm{i}$} & \multirow{3}{*}{ CV, CVD, CVDF, CVF } & $14.49 \pm 1.58$ \\
\hline & & $10.91 \pm 1.52$ \\
\hline & & 0.81 \\
\hline & \multirow{3}{*}{ FORSUD } & $15.64 \pm 1.08$ \\
\hline & & $4.05 \pm 0.60$ \\
\hline & & 0.94 \\
\hline \multirow{6}{*}{$\mathrm{C} 4 \mathrm{i}+\mathrm{C} 5 \mathrm{i}$} & \multirow{3}{*}{ CV, CVD, CVDF, CVF } & $12.12 \pm 1.56$ \\
\hline & & $5.45 \pm 0.29$ \\
\hline & & 0.86 \\
\hline & \multirow{3}{*}{ FORSUD } & $15.19 \pm 1.15$ \\
\hline & & $1.95 \pm 0.29$ \\
\hline & & 0.94 \\
\hline
\end{tabular}




\subsection{Economic and Environmental Implications of this Study}

The findings of this study have relevant economic and environmental implications for the animal production industry, for the management of animal dejections and for the treatment of urban biowastes. The benefits for the animal production industry might derive from enhanced animal growth rate obtained through the use of SBO compared to other commercial diet supplements. The environmental benefits would derive from the production of animal dejections with reduced ammonia and/or inorganic N content. Such materials would reduced risks connected to the use of manure in agriculture, to its nitrification and/or denitrification in soil, and to leaching or releasing toxic products into ground and surface water and/or air. A similar problem involves also waste treatment practices performing anaerobic digestion of animal manure and vegetable residues (Strik et al., 2006). In this case, $\mathrm{N}$ mineralization occurring during fermentation leads to high ammonia concentration, process inhibition, decreased COD removal efficiency, reduced biogas production, malodor, poor biogas quality and accumulation of inorganic $\mathrm{N}$ compounds into the process digestate. This fact limits the use of the digestate in agriculture (Lukehurst et al., 2010), and therefore requires treatment. Demonstration of such benefits would help to establish a market for SBO. The expected revenue from SBO sales might in turn provide enough justification for integrating current UBW treatment plant, producing biogas and/or compost only, with facilities for the production of SBO. This would be the first step to build a new scenario by which UBW treatment plan were turned into biorefinery for the production of biofuel, chemicals and consumer's products. Large economic and environmental benefits have been already estimated for this scenario (Montoneri et al., 2011b).

\section{Conclusion}

With reference to the first objective of the present study stated in the Introduction section, the results show that UBW sourced SBO can affect protein metabolism in animal ileum. The SBO effects on ammonia reduction have been found of the same magnitude as for fossil HS (Ji et al., 2006). Clearly, due to their origin SBO appear favored products for economic and environmental reasons. Use of SBO as animal feed supplement allows valorizing UBW as source of high added value products, thus decreasing their disposal cost (Montoneri et al., 2011b). On the contrary, use of HS would contribute to the depletion of fossil sources.

In relation to the second objective of this study stated in the Introduction section, the results show that all compost sourced SBO induce significant reduction of the mineralization of organic $\mathrm{N}$ during in vitro protein fermentation in the presence of pigs' cecal content used as incubation liquor. By comparison, the SBO isolated from the digestate of food residues' anaerobic treatment have opposite effect.

For the economic and environmental perspectives posed by the above results, in vivo studies seem worthwhile in order to effectively assess whether the use of SBO as diet supplements enhanced pigs' growth during the weaning phase and/or lowered the environmental impact of animal dejections. Further studies are also suggested to investigate the full potential of the above products as modulators of anaerobic fermentation processes occurring in bioreactors processing biowastes, in landfill sites and in soil where manure and biofertilizers are used for conditioning and/or agriculture purpose.

\section{Acknowledgements}

This work was carried out with the aid of Regione Piemonte Cipe 2006 funds within the Biochemenergy project. The authors are grateful to Acea Pinerolese Industriale in Pinerolo, TO (Italy), for supplying the refuse materials sampled from their waste treatment plant and to Studio Chiono ed Associati in Rivarolo Canavese, TO (Italy), for making available the SBO production test facility.

\section{References}

A. O. A. C. (2000). Official Methods of Analysis (17th ed.). Association of Official Analytical Chemist. Virginia, U.S.

Casadei, G., Grilli, E., \& Piva, A. (2009). Pediocin A modulates intestinal microflora in swine in vitro intestinal fermentations. J. Anim. Sci., 87, 2020-2028.

Ji, F., McGlone, J. J., \& Kim, S. W. (2006). Effects of dietary humic substances on pig growth performance, carcass characteristics, and ammonia emission. J. Anim Sci., 84, 2482-2490.

Lukehurst, C., Frost, P., \& Al Seadi, T. (2010). Task 37-Utilisation of digestate from biogas plants as biofertiliser, 1-21. Retrieved August 29, 2012 from http://www.iea-biogas.net (accessed August 29, 2012).

Menke, K. H., Raab, L., Salewski, A., Steingass, H., Fritz, D., \& Schneider, W. (1979). The estimation of the digestibility and metabolizable energycontent of ruminant feedingstuffs from the gas production when they areincubated with rumen liquor in vitro. J. Agric. Sci., 93, 217-222. 
Mista, D. (2007). The Effect of Dietary Supplement-Humobentofet on Rabbit Caecal Parameters of Microbial Fermentation at in Vitro Study. Electronic Journal of Polish Agricultural Universities, 10. Retrieved August 30, 2012 from http://www.ejpau.media.pl/volume10/issue4/art-13.html

Montoneri, E., Boffa, V., Savarino, P., Perrone, D. G., Ghezzo, M., \& Montoneri, C. (2011a). Acid soluble bio-organic substances isolated from urban bio-waste. Chemical composition and properties of products. Waste Management, 31, 10-17.

Montoneri, E., Mainero, D., Boffa, V., Perrone, D. G., \& Montoneri, C. (2011b). Biochemenergy: a project to turn a urban wastes treatment plant into biorefinery for the production of energy, chemicals and consumer's products with friendly enviromental impact. Int. J. Global Environmental Issues, 11, 170-196.

Piva, A., Grilli, E., Fabbri, L., Pizzamiglio, V., Gatta, P. P., Galvagno, F., ... Patterson J. A. (2008). Intestinal metabolism of weaned piglets fed with a typical United States or European diet with or without supplementation of tributyrin and latitol. J. Anim. Sci., 86, 2952-2961.

Piva, A., Casadei, G., \& Biagi, G. (2002). An organic acid blend can modulate swine intestinal fermentation and reduce microbial proteolysis. Can. J. Anim. Sci., 82, 527-532, and references therein.

Piva, A., Meola, E., \& Panciroli, A. (1995). Effect of Pediococcus pentosaceus FBB61, pedici A producer strain, in caecal fermentations. J. Applied Bacteriology, 76, 616-620.

Sortino, O., Dipasquale, M., Montoneri, E., Tomasso, L., Avetta, P., \& Bianco, P. A. (2012). 90\% yield increase of red pepper with unexpectedly low doses of compost soluble substances. Agronomy for Sustainable Development. http://dx.doi.org/10.1007/s13593-012-0117-6

Strik, D. P. B. T. B., Domnanovich, A. M., \& Holubar, P. (2006). A pH-based control of ammonia in biogas during anaerobic digestion of artificial pig manure and maize silage. Process Biochemistry, 41, 1235-1238. 